\title{
Isolation of Listeria monocytogenes and Listeria ivanovii and its Nitric Oxide Expression Level in Serum, Brain and Reproductive Organs of Sheep
}

\author{
Nitasha Sambyal ${ }^{1}$, Varun Bassessar $^{2}$, Rahul Singh ${ }^{2 *}$, Nafia Rufai ${ }^{3}$ and Bharat Mengi ${ }^{4}$ \\ ${ }^{1}$ Department of Veterinary Public Health and Epidemiology, ${ }^{2}$ Department of Veterinary \\ Pathology, Khalsa College of Veterinary and Animal Sciences, Amritsar (143002), India \\ ${ }^{3}$ Sher-e-Kashmir University of Agricultural Sciences and Technology, \\ Jammu (180016), India \\ ${ }^{4}$ Obihiro University of Agriculture and Veterinary Medicine (OUAVM), Hokkaido, Japan \\ *Corresponding author
}

\begin{tabular}{l} 
K e y w o r d s \\
$\begin{array}{l}\text { Listeria ivanovii, } L . \\
\text { monocytogenes, } \\
\text { Sheep, Prevalence }\end{array}$ \\
\hline Article Info \\
$\begin{array}{l}\text { Accepted: } \\
10 \text { July } 2020 \\
\text { Available Online: } \\
10 \text { August } 2020\end{array}$ \\
\hline
\end{tabular}

\section{A B S T R A C T}

Two species of Listeria are pathogenic; L. monocytogenes infects humans and animals, and $L$. ivanovii infects ruminants only have been considered. While infection with L. monocytogenes and L. ivanovii are known as important causes of abortion and reproductive failure in ruminants and the role of nitric oxide (NO) expression in different organs of affected animals in India is limited. Therefore, the current study, $(n=78)$ serum and organs (comprising of 26 ovaries, 26 uterus and 26 brain) samples from the local abattoir in and around Jammu region were taken and evaluate for the presences of Listeria spp. by employing two fold enrichment procedure for isolation and confirmed by biochemical tests. Then further, pathogenicity of isolated were confirmed by Phosphatidylinositol-specific phospholipase C (PI-PLC) assay. Out of them $L$. monocytogenes was detected in 5 samples i.e. 3 in uterus, 1 in ovary and 1 in brain, and $L$. ivanovii was isolated only in 3 uterus sample with over-all prevalence of $6.41 \%$ and $3.85 \%$ respectively. The prevalence of other Listeria spp. in the sample was $3.85 \%$. Further, we were found high concentration of NO in Listeria spp. infected samples in comparison to the Listeria spp. was not isolated. This study demonstrated that Listeria spp. (mainly L. monocytogenes and L. ivanovii) infected sheep showed very high NO concentration level compared to without infected animals. The functional role of nitric oxide (either iNOS or nNOS) needs to be further studied in natural and experimental models with Listeria spp. infection.

\section{Introduction}

Listeria spp. is a gram positive facultative intracellular and invasive bacterium. The genus Listeria contains 2 pathogenic species, L. monocytogenes and L. ivanovii (Seeliger et al., 1986; Lotfollahi et al., 2017). L. ivanovii infection is associated with fetal death, stillbirths and premature births in ruminants, although it is less common 
than L. monocytogenes (Low and Donachie, 1997). They both invade host cells, replicate in the cytosol after phagosomal escape, and spread from cell to cell by polymerizing actin. However, each species appears to infect different hosts: L. monocytogenes infects humans and ruminants, whereas L. ivanovii is thought to infect ruminants only (VázquezBoland et al., 2001). It is an emerging foodborne zoonotic pathogen of high public health significance and is responsible for $60 \%$ of hospitalizations annual mortality of 20$40 \%$ (Low and Donachie, 1997). The ruminants are the major reservoir of $L$. monocytogenes in which infection is generally asymptomatic but could be manifested as encephalitis, abortion, septicemia and mastitis with considerable high economic loses (Low and Donachie, 1997).

It is known that $\mathrm{NO}$ can directly and indirectly modulate the immune response through diverse mechanisms within macrophages and other phagocytes. That is, it works as a microbiostatic or microbicidal agent or modulates biological activity of innate and acquired immunity cell lines (Heck et al., 2005). Basic function of NO in immune system is its contribution in protective immunity against intracellular pathogens including viruses, bacteria and protozoa (Nathan 1991, Fang 1997, De Groote and Fang 1995 Singh et al., 2018a,b). Its mechanism depends upon production of NO and superoxide (O2) by activated macrophages, which causes formation of peroxynitrite anion (ONOO-), which causes effect on pathogens. (Hess et al., 2005; Sun et $a l ., 2006)$. Thus the knowledge of NO is not only important in understanding immunology but it is also a foundation for the development of new approaches for the management and treatment of various diseases, including Listeria spp. Based on above information, the aimed of this study to isolation and monitor NO expression level in serum, ovary, uterus and brain of naturally affected slaughtered sheep with Listeria. spp. infection.

\section{Materials and Methods}

In the current study the $(\mathrm{n}=78)$ serum and organs (comprising of 26 ovaries, 26 brain and 26 uterus) samples from the local abattoir in and around Jammu were taken and evaluate for the presences of Listeria spp. in meat and the concentration of nitric oxide in the same samples were studied. Reproductive tracts along with the brain of same animals were collected and transported to the laboratory in Phosphate Buffered saline (PBS) in an ice box within 30 minutes. Hypothalamus was separated carefully from the brain, thoroughly rinsed in physiological saline and stored at $20^{\circ} \mathrm{C}$ till further use.

Follicular fluid was aspirated by using a separate hypodermic tuberculin syringe from each ovary. It was collected by applying slight pressure to avoid additional traumatisation of follicles. Aspirated fluid was centrifuged at $3000 \mathrm{rpm}$ for 15 minutes to remove cellular debris. The sample was kept at $-20^{\circ} \mathrm{C}$ till further use. Samples of reproductive tissues (ovarian, oviductal and uterine tissues) were collected aseptically and kept at $-20^{\circ} \mathrm{C}$ till further use.

\section{Isolation of Listeria spp.}

Isolation of Listeria species was based on two fold enrichment procedure as recommended by USDA 2009 and as described by Loncarevic, et al., (2006) with suitable modifications. Briefly, approximately $10 \mathrm{~g}$ of samples were directly inoculated into $90 \mathrm{ml}$ of University of Vermont-1 (UVM-1, Himedia Labs, Mumbai, India) and incubated overnight at $30^{\circ} \mathrm{C}$. The enriched UVM-1 inoculum $(0.1 \mathrm{ml})$ was then transferred to 10 $\mathrm{ml}$ of fraser broth and incubated overnight at $30{ }^{\circ} \mathrm{C}$. The inoculum from the enriched fraser 
broth was streaked on oxford agar and inoculated plates were incubated at $37{ }^{\circ} \mathrm{C}$ for $48 \mathrm{~h}$. The typical small, round greyish blackish colonies of about $0.5 \mathrm{~mm}$ diameter surrounded by diffuse black zone of aesculin hydrolysis were presumed to be Listeria spp (Fig.1). The presumed colonies of Listeria (at least 3/plate) were further confirmed.

\section{Confirmation of the isolates}

These isolates were further subjected to different biochemical tests according to standard procedure described by Cruickshank et al., (1975) and Cowan (1977). Typical colonies were verified by Gram's staining, catalase reaction, tumbling motility at 20-25 ${ }^{\circ} \mathrm{C}$, methyl red-Voges Proskauer (MR-VP) reactions, CAMP test with Staphylococcus aureus and Rodococcus equi, nitrate reduction, fermentation of sugars (rhamnose, xylose, mannitol and $\alpha$-methyl-D-mannoside) and hemolysis on 5\% sheep blood agar (SBA). The isolates were further tested for their pathogenicity.

\section{Pathogenicity test}

Phosphatidylinositol-specific phospholipase C (PI-PLC) assay. All the biochemically characterized Listeria isolates were assayed for PI-PLC activity as per the method of Notermans et al., (1991) and Ottoviani et al., (1997) with certain modifications.

The Listeria isolates were grown overnight onto L. mono Confirmatory Agar Base supplemented with L. mono Selective Supplement I \& II and L. mono Enrichment Supplement II at $35-37^{\circ} \mathrm{C}$. Phospholipase C enzyme produced by $L$. monocytogenes and $L$. ivanovii hydrolyses the purified substrate (FD227) added to the medium and results in the formation of an opaque halo around the colonies (Fig. 2 \&3).
It also contains alpha-Methyl D-mannoside, its fermentation is shown by $L$. monocytogenes. Thus, Differentiation between L. monocytogenes and L. ivanovii is achieved on the basis of alpha -Methyl Dmannoside utilization and PIPLC activity.

\section{Determination of total nitrate}

The total nitrate and nitrite estimation in hypothalamus, follicular fluid, ovarian tissue, fallopian tube and uterus was carried out as per the modified method described by Sastry et al., (2002). The method performed is as follows: Reproductive tissues (ovarian, oviductal and uterine tissues) and hypothalamus were weighed and homogenized in ice-cold 1.0M PBS with a pH of 7.4. The homogenate was then subjected to centrifugation at $4000 \mathrm{~g}$ for 10 minutes at $4^{0} \mathrm{C}$. The supernatant was then collected in fresh tubes. Alongside test samples, standards were also processed. $100 \mu \mathrm{L}$ of supernatant (test sample) and standard solutions were taken in test tubes and to them $400 \mu \mathrm{L}$ of 50 $\mathrm{mM}$ carbonate buffer was added to each test tube.

\section{Activation of copper-cadmium alloy}

Copper-cadmium alloy filings were washed twice with $100 \mathrm{ml}$ of deionised distilled water in a $150 \mathrm{ml}$ Erlenmeyer flask. After discarding the supernatant, the filings were washed with $100 \mathrm{ml} 0.5 \mathrm{~N} \mathrm{HCl}$. This washing removed the hydroxide of cadmium $\mathrm{Cd}(\mathrm{OH})_{2}$, which resulted in a change in texture and color. The filings appeared gray and slightly buoyant. These activated filings are quickly washed twice with $100 \mathrm{ml}$ of $0.1 \mathrm{~N} \mathrm{HCl}$ and stored in $50 \mathrm{ml}$ of $0.1 \mathrm{M} \mathrm{HCl}$ at $2-8^{\circ} \mathrm{C}$ till further use. After activation approximately $150 \mathrm{mg}$ of dried copper-cadmium alloy was added in the test and standard sample tubes followed by incubation of test tube for $1 \mathrm{hr}$ at $37^{0} \mathrm{C}$ with thorough shaking. This incubation 
causes full conversion of nitrate to nitrite. After incubation, $100 \mu \mathrm{L}$ of $0.35 \mathrm{M}$ Sodium hydroxide was added to halt the reaction; followed by adding $400 \mu \mathrm{L}$ of $120 \mathrm{mM}$ Zinc sulphate solution on a vortex mixture. Zinc sulphate leads to deproteinization (white precipitation was seen). The test tubes were allowed to stand for 10 minutes. The tubes were centrifuged at $4000 \mathrm{~g}$ for 10 minutes at room temperature. Precipitate settled down and clear transparent supernatant stood up. Then these samples were subjected to macro assay.

\section{Macro-assay}

Aliquots $(500 \mu \mathrm{L})$ of clear supernatant were transferred to another test tube and $250 \mu \mathrm{L}$ of $1.0 \%$ Sulfanilamide (prepared in $3 \mathrm{~N} \mathrm{HCl}$ ) and $250 \mu \mathrm{L}$ of $0.1 \% \mathrm{~N}$-naphthylethylenediamine (prepared in water) were added with shaking. After 10minutes the absorbance was measured at $545 \mathrm{~nm}$ against a blank containing the same concentration of ingredients without any test sample.

\section{Results and Discussion}

Listeria spp. are ubiquitous organisms and an increasing number of recent reports show prevalence of L. monocytogenes. Listeria spp. have been isolated from various different environments, including soil, surface water, vegetation, sewage, animal feeds, farm environments, and food-processing environments (Lotfollahi et al., 2017). Of the six bacteria species within the genus, $L$. ivanovii is one of the two pathogenic species (the other being $L$. monocytogenes). It behaves like L. monocytogenes, but is found almost exclusively in ruminants (mainly sheep).

In the present study, out of $(n=78)$ serum and organs (comprising of 26 uterus, 26 ovaries and 26 brain) samples, L. monocytogenes was detected in 5 samples i.e. 3 in uterus, 1 in ovary and 1 in brain, with the over-all prevalence of $6.41 \%$. On other hand, L. ivanovii was isolated only in 3 uterus sample with the prevalence of $3.85 \%$.

Table.1 Concentration of Nitric Oxide (NO) and presence and absence of Listeria spp. in corresponding tissues

\begin{tabular}{|c|c|c|c|c|c|c|c|}
\hline \multirow{2}{*}{$\begin{array}{l}\text { Sample } \\
\text { number }\end{array}$} & \multicolumn{2}{|c|}{ Uterus } & \multicolumn{2}{|c|}{ Ovary } & \multicolumn{2}{|c|}{ Brain } & \multirow{2}{*}{$\begin{array}{c}\text { NO } \\
\text { level in } \\
\text { Serum }\end{array}$} \\
\hline & $\begin{array}{l}\text { NO } \\
\text { level }\end{array}$ & Isolation & $\begin{array}{c}\text { NO } \\
\text { level }\end{array}$ & Isolation & $\begin{array}{c}\text { NO } \\
\text { level }\end{array}$ & Isolation & \\
\hline $\begin{array}{c}\text { Mean of } 17 \\
\text { negative } \\
\text { samples }\end{array}$ & 17.98 & - & 16.35 & - & 15.74 & - & 26.82 \\
\hline 7 & 51.60 & L. mono & 40.80 & L. mono & 40.00 & L. mono & 44.80 \\
\hline 8 & 16.00 & - & 30.00 & L. spp. & 35.60 & - & 40.80 \\
\hline 10 & 45.60 & L. ivano & 31.60 & - & 38.80 & - & 55.60 \\
\hline 17 & 38.40 & L. ivano & 22.40 & - & 20.40 & - & 44.80 \\
\hline 18 & 36.80 & L. mono & 15.20 & - & 32.40 & - & 146.80 \\
\hline 20 & 18.00 & - & 20.00 & - & 35.20 & L. spp. & 16.40 \\
\hline 22 & 46.40 & L. ivano & 11.60 & - & 13.20 & - & 74.00 \\
\hline 23 & 46.80 & L. spp. & 13.60 & - & 10.80 & - & 39.60 \\
\hline 27 & 50.40 & L. mono & 23.60 & - & 8.00 & - & 46.00 \\
\hline
\end{tabular}


Fig.1 Listeria spp. on oxford agar

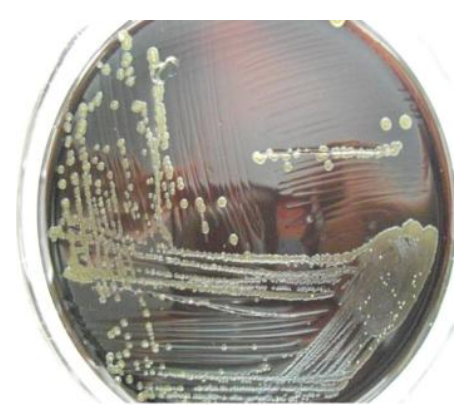

Fig.2 Listeria moncytogenes on L. mono confirmatory agar

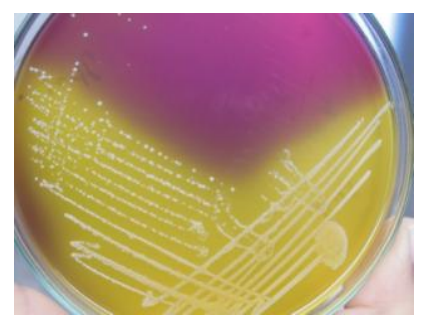

Fig.3 Listeria ivanovii on L. mono confirmatory agar

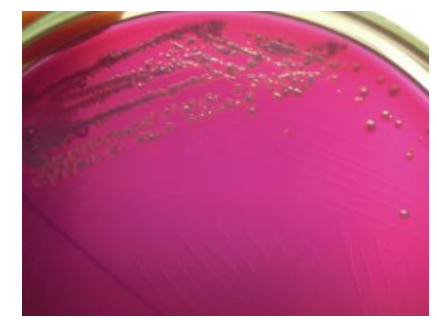

The prevalence of other Listeria spp. in the sample was $3.85 \%$. All the isolates were gram positive, cocco-bacillus, positive for catalase, Methyl Red and Voges-Proskauer reaction. They showed negative reaction for indole, oxidase, $\mathrm{H}_{2} \mathrm{~S}$, urea hydrolysis, nitrate reduction and gelatin liquefaction. But showed characteristic tumbling motility when kept in the broth at $25^{\circ} \mathrm{C}$ for $18-24$ hrs. In our study 8 samples showed typical $\beta$-haemolysis when streaked on HBA (5\%), for $24-48 \mathrm{hr}$ at $37^{\circ} \mathrm{C}$. But no hemolysis pattern was observed in 3 isolates. All the 8 positive haemolytic isolates were subjected to CAMP test and
Phosphatidylinositol-specific phospholipase C (PIPLC) assay. 5 isolates showed enhancement on Staphylococcus aureus streak and 3 on R. equi streak on HBA plate. Similar results were obtained on PIPLC assay, thus 5 isolated showing yellow colonies and halo zone in PIPLC assay were confirmed as L. monocytogenes and the 3 isolates showing purple colonies with halo were confirmed as L. ivanovii.

The prevalence recorded in present investigation is lower as compared to the reported $30 \%$ prevalence of Listeria spp. from 
69 brain samples of goats collected at the time of post-mortem (Shivasharanappa et al., 2014). L. monocytogenes can also be isolated from the surface and underground waters, improperly fermented silage, sewage sludge, slaughter wastes, animal and human faeces, foodstuffs, and food industry plants (Ivanek et al., 2006). In the current study it was found that there was high concentration or expression of NO in Listeria infected tissues in comparison to the tissues where Listeria was not isolated (Table.1).

Our findings are similar to the reports given by Brosnan et al., (1994) and Moncada et al., (1991), which suggests the involvement of NO (central nervous system) in pathological sequelae. It was found that (sample 7), there is increase in nitric oxide concentration in the brains of Listeria infected sheep. Therefore, nitric oxide produced by neutrophils and macrophages may play an important role in eliminating L. monocytogenes and in the histopathology of brain tissue. Even though Listeria spread to other organs but powerful anti-listerial mechanisms of $\mathrm{NO}$ led to acomplete elimination of $L$. monocytogenes from the brain and other organs. There was isolation of L. monocytogenes from sample 18 (uterus), but the concentration of $\mathrm{NO}$ was found very high in the serum in comparison to the tissue. It may suggest chronic infection in the uterus, but the high NO level of serum does not result in spread of infection to other organs. However some earlier workers suggest that the role of $\mathrm{NO}^{\circ}$ as anti-listerial activity is controversial (Ohya et al., 1998; Samsom et al., (1996). But Remer et al., (2001) had reported that there is neutralize of L. monocytogenes by the production of NO from macrophages. The role of $\mathrm{NO}$ generation in ruminant listeriosis remains to be studied. Another question raises that whether NO generation is essential for the elimination of L. monocytogenes in the brain. However some studies show that killing of L. monocytogenes in-vitro was dependant on NO (Fehr et al., 1997). Although L. monocytogenes are by far the leading cause of human and animal's listeriosis, and its role of high NO in infected sheep. But, our report shows that L. ivanovii infected can also cause enhance expression of NO levels. As we know, Listeriosis causes sudden death in animals, thus the functional role of nitric oxide (either iNOS or nNOS) in Listeria spp. affected animals needs to be further studied.

\section{Acknowledgements}

The authors gratefully acknowledge the Dean, Sher-e-Kashmir University of Agricultural Sciences and Technology, Jammu. , India for providing necessary facilities for the study.

\section{References}

Brosnan, C.F., Battistini, L., Raine, C.S., Dickson, D.W., Casadevall, A. and Lee, S.C.1994. Reactive nitrogen intermediates in human neuropathology: an overview. Dev. Neurosci., 16(4): 152-161.

Cowan, S.T. 1977. Manual for the identification of medical bacteria, second edition, Cambridge University Press, N. Y.

Cruickshank, R., Duguid, J.P., Marimon, B.P. and Swain, B.P.1975. Medical Microbiology, 12 $2^{\text {th }}$ edn., Churchill, Livingstone, Edinburgh, London.

De Groote, M.A. and Fang, F.C. 1995. NO inhibitions: antimicrobial properties of nitric oxide. Clin. Infect. Dis, 21 (Suppl 2): S162-165.

Fang, F.C. 1997. Perspectives series: host/pathogen interactions. Mechanisms of nitric oxide-related antimicrobial activity. J. Clin. Invest. 99: 2818-2825.

Fehr, T., Schoedon, G., Odermatt, B., Holtschke, T., Schneemann, M., 
Bachmannm M.F., Mak, T.W., Horak, I. and Zinkernagel, R.M.1997. Crucial role of interferon consensus sequence binding protein, but neither of interferon regulatory factor 1 nor of nitric oxide synthesis for protection against murine listeriosis. J. Exp. Med., 185(5): 921932.

Heck, D.E., Kagan, V.E., Shvedova, A.A. and Laskin, J.D. 2005. An epigrammatic (abridged) recounting of the myriad tales of astonishing deeds and dire consequences pertaining to nitric oxide and reactive oxygen species in mitochondria with an ancillary missive concerning the origins of apoptosis. Toxicol., 208: 259-71

Hess, D.T., Matsumoto, S.O., Marshall, H.E. and Stamler, J.S. 2005. Protein Snitrosylation: purview and parameters. Nat. Rev. Mol. Cell Biol.. 6: 150-166.

Iwahashi, T., Inoue, A., Koh, C.S., Shin, T.K. and Kim, B.S. 1999. Expression and potential role of inducible nitric oxide synthase in the central nervous system of Theiler's murine encephalomyelitis virus-induced demyelinating disease. Cell. Immunol., 194: 186-193.

Loncarevic, S. and Johansson, T. 2006. Collaborative study of the revised NMKL method No. 136: Listeria monocytogenes, Detection and enumeration in foods and feeds. Test report, National Veterinary Institute, Oslo, Norway.

Lotfollahi, L., Chaharbalesh, A., Razaee, M.A. and Hasani, A. 2017. Prevalence, antimicrobial susceptibility \& Multiplex PCR- serotyping of Listeria monocytogenes isolated from humans, foods and livestock in Iran. Microbial Pathog., 107: 425-429.

Low, J.C. and Donachie, W. 1997. A review of Listeria monocytogenes and listeriosis. Vet. J., 153(1): 9-29.

Moncada, S., Palmer, R.M.J. and Higgs, E.A.
1991. Nitric oxide: physiology, pathophysiology, pharmacology. Pharmacol. Rev., 43: 109-134

Nathan, C.F. and Hibbs, J.B. 1991. Role of nitric oxide synthesis in macrophage antimicrobial activity. Curr. Opin. Clin. Immunol., 3(1):65-70.

Notermans, S.H.W., Dufrenne, J., LeimeisterWachter, M., Domann, E. and Chakraborty, $\quad$ T. 1991. Phosphatidylinositol-specific phospholipase $\mathrm{C}$ activity as a marker to distinguish between pathogenic and non-pathogenic Listeria species. Appl. Env. Microbiol., 57: 2666-2670.

Ohya, S., Tanabe, Y., Makino, M., Nomura, T., Xiong, H., Arakawa, M. and Mitsuyama, M. 1998. The contributions of reactive oxygen intermediates and reactive nitrogen intermediates to listericidal mechanisms differ in macrophages activated pre-and post infection. Infect. Immun., 66(9): 4043-9.

Ottaviani, F., Ottaviani, M. and Agosti, M. 1997. Industrie. Alimentari., 36: 1-3. .

Remer, K.A., Jungi, T.W., Fatzer, R.. Tauber, M.G. and Leib, S.L. 2001. Nitric oxide is protective in listeric meningoencephalitis of rats. Infect. Immun., 69: 4086-4093,

Samsom, J.N., Langermans, J.A., Groeneveld, P.H. and van Furth, R.A. 1996. Acquired resistance against a secondary infection with Listeria monocytogenes in mice is not dependent on reactive nitrogen intermediates. Infect. Immun., 64(4):1197-202.

Seeliger, H.P.R., Jones, D., Sneath, P.H.A., Mair, N.S., Sharpe, M.E. and Holt, J.G. 1986. Editors. Bergey's manual of systematic bacteriology, Vol. 2. Baltimore: Williams \& Wilkins. Pp. 1235-1245.

Shivasharanappa, N., Gupta, V.K., Pawaiya, R.S., Reddy, G.B.M., Kumar, A. and Barbuddhe, S.B. 2014. Isolation and 
characterization of Listeria monocytogenes from goat brain. Adv. Anim. Vet. Sci., 35:12-15.

Singh, R., Singh, S., Singh, R., Dhama, K., Singh, K.P., Singh, S. and Singh, V., 2018a. Epidemiological study of Mannheimia haemolytica infection in the sheep and goats population, India. Biological Rhythm Research, pp.1-10.

Singh, R., Singh, S., Singh, R., Varshney, R., Dhama, K., Kumari, S., Singh, K.P., Dar, J.A., Kashyap, G., Kamdi, B. and Kumar, P., 2018b. PathoEpidemiological study of jaagsiekte sheep retrovirus infection in the sheep and goats population, India. Biological Rhythm Research, pp.1-15.

Sun, J., Steenbergen, C. and Murphy E. 2006. S-nitrosylation: NO-related redox signaling to protect against oxidative stress. Antioxid. Redox Signal., 8(910):1693-1705.

Vázquez-Boland, J.A., Kuhn, M., Berche, P., Chakraborty, T., Domínguez-Bernal, G. and Goebel, W. 2001. Listeria pathogenesis and molecular virulence determinants. Clin. Microbiol. Rev., 14:584-640.

\section{How to cite this article:}

Nitasha Sambyal, Varun Bassessar, Rahul Singh, Nafia Rufai and Bharat Mengi. 2020. Isolation of Listeria monocytogenes and Listeria ivanovii and its Nitric Oxide Expression Level in Serum, Brain and Reproductive Organs of Sheep. Int.J.Curr.Microbiol.App.Sci. 9(08): 223230. doi: https://doi.org/10.20546/ijcmas.2020.908.025 